\title{
Cryptosporidium infection in a veal calf cohort in France: molecular characterization of species in a longitudinal study
} Jérôme Follet ${ }^{1 *}$, Karine Guyot ${ }^{2,3,4}$, Hélène Leruste', Anne Follet-Dumoulin ${ }^{5}$, Ourida Hammouma-Ghelboun ${ }^{1}$,
Gabriela Certad

\begin{abstract}
Feces from 142 animals were collected on 15 farms in the region of Brittany, France. Each sample was directly collected from the rectum of the animal and identified with the ear tag number. Animals were sampled three times, at 5, 15 and 22 weeks of age. After DNA extraction from stool samples, nested PCR was performed to amplify partial 18S-rDNA and $60 \mathrm{kDa}$ glycoprotein genes of Cryptosporidium. The parasite was detected on all farms. One hundred out of 142 calves (70.4\%) were found to be parasitized by Cryptosporidium. Amplified fragments were sequenced for Cryptosporidium species identification and revealed the presence of C. parvum (43.8\%), C. ryanae (28.5\%), and C. bovis (27\%). One animal was infected with Cryptosporidium ubiquitum. The prevalence of these species was related to the age of the animal. C. parvum caused $86.7 \%$ of Cryptosporidium infections in 5-week-old calves but only $1.7 \%$ in 15-week-old animals. The analysis of the results showed that animals could be infected successively by C. parvum, C. ryanae, and C. bovis for the study period. C. parvum gp60 genotyping identifies 6 lla subtypes of which 74.5\% were represented by IlaA15G2R1. This work confirms previous studies in other countries showing that zoonotic C. parvum is the dominant species seen in young calves.
\end{abstract}

\section{Introduction}

Cryptosporidium is a genus of protozoan parasites infecting a wide range of hosts [1]. All groups of vertebrates are susceptible to Cryptosporidium infection worldwide. This parasite is the etiological agent of cryptosporidiosis, which is mainly characterized by diarrhea in humans and livestock. Massive outbreaks of enteritis in people such as in Milwaukee, Wisconsin (USA) have increased public awareness of this parasite [2]. In humans, the prevalence and severity of infection increase in immunodeficient individuals such as AIDS patients. In immunocompetent patients, the disease is self-limited [3]. No drug therapy is yet available and the high resistance of oocysts to environmental conditions and chemical treatment make cryptosporidiosis difficult to control [4]. Cattle have been considered to be a primary reservoir for Cryptosporidium oocysts for zoonotic C. parvum [5]. These animals could

\footnotetext{
* Correspondence: jerome.follet@isa-lille.fr

'Laboratoire Biotechnologies et Gestion des Agents Pathogènes, Institut Supérieur d'Agriculture, 59048 Lille, France

Full list of author information is available at the end of the article
}

be a risk factor via environmental contamination from their manure being spread on farmland or their grazing on watersheds [6]. On farms, transmission of Cryptosporidium spp. can result from ingestion of contaminated food or water, by direct transmission from host to host, or through insect vectors [7]. In cattle, infection by Cryptosporidium spp. was first reported in 1971 [8]. Since vaccines have become commercially available against Escherichia coli K99, rotavirus, and coronavirus, Cryptosporidium has emerged as the main neonatal diarrheic agent in calves [9]. In farm animals, the economic impact is related to morbidity, mortality and growth retardation [10]. Among the 24 species previously described (if the three fish species are accepted without complete genetic characterization) [1,11-13], C. parvum, C. bovis, C. ryanae and $C$. andersoni usually infect cattle. C. parvum has zoonotic potential and is a frequent cause of human cryptosporidiosis [14]. C. bovis and C. ryanae have not been found in humans and there is only one description of C. andersoni in a patient [15]. Recent reports have 
described an age-related distribution of these aforementioned species in dairy cattle on the east coast of the United States [16-18], India, China, Georgia [19], Malaysia [20], and Denmark [21]. The most prevalent species were C. parvum in preweaned calves, C. ryanae and C. bovis in postweaned calves and $C$. andersoni in adult cows [16,17].

In France, previous studies on the prevalence of Cryptosporidium in cattle were based on microscopic determination [22] or coproantigen detection using ELISA [23]. These studies on dairy calves reported a within herd prevalence of Cryptosporidium without identifying species or the relation to the host's age. The present study was conducted in 15 farms in Brittany, France to determine the prevalence of Cryptosporidium in veal calves. We used genotyping and subtyping for the molecular study of Cryptosporidium isolates. Follow-up of the same animal allowed us to determine the outcome of the infection and the age distribution of Cryptosporidium species.

\section{Material and methods}

\section{Specimen sources and collection}

Fifteen fattening units in Brittany (France) were included in this work. They belonged to three industrial veal producers representative of integrators in France and did not present any known history of Cryptosporidium infection. These farms were located in four administrative regions (Figure 1): Côtes d'Armor (CA1-CA3), Morbihan (MO1), Ile-et-Vilaine (IV1-IV5), and Mayenne (MA1-MA6). During the summer and autumn of 2007, all farms were visited three times and fecal samples were taken from 142 animals exhibiting diarrhea at the age of 5 weeks old. Calves arrived in fattening units at the age of 2 weeks old and were confined in small groups from four to six animals per pen. Because of a concomitant welfare study [24], calves had to stay 2 to 3 weeks without any external stress despite the farmer's presence. At the age of 22 weeks old, calves were finally sent to the slaughterhouse. Consequently, sampling was done at the ages of 5 weeks, 15 weeks, and 22 weeks (Table 1 ). These points of sampling corresponded to the beginning, the middle and the end of the fattening period. Fecal samples were collected and shipped by a veterinarian. Collectors respected the following criteria: use of a single pair of latex gloves per animal, a single plastic sterile cup per animal, and collection of at least $5 \mathrm{~g}$ of feces per sample. Feces were collected directly from the rectum of each animal and stored at $4{ }^{\circ} \mathrm{C}$ in potassium dichromate $(2.5 \% \mathrm{wt} / \mathrm{vol})$ until processed. Cups were capped, labeled with the

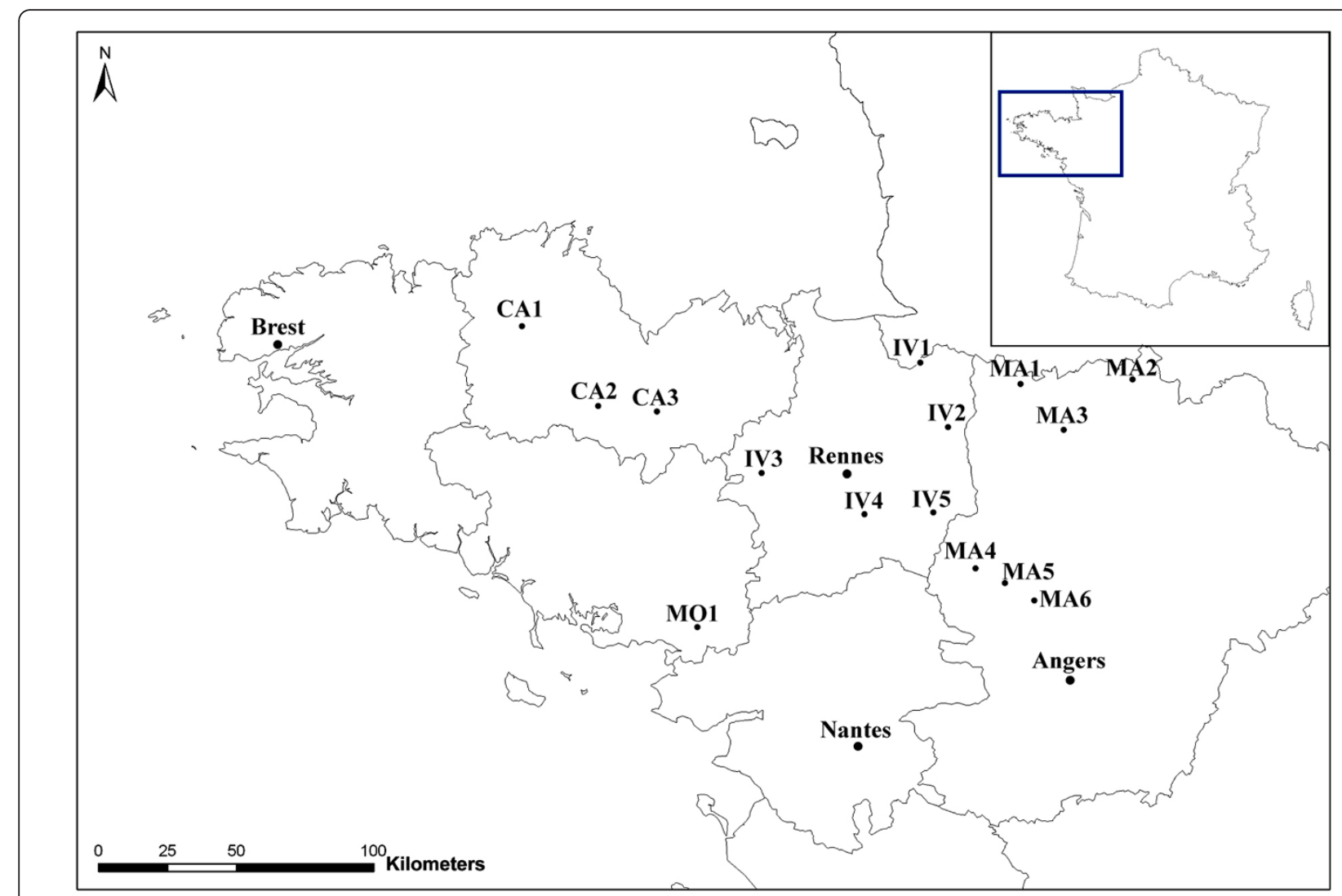

Figure 1 Map of administrative regions in Brittany showing the location of farms included in the study: Côtes d'Armor (CA), lle-etVilaine (IV), Mayenne (MA), and Morbihan (MO) in France. 
Table 1 Cryptosporidium prevalence in veal herds found in Brittany farms according to animal age

\begin{tabular}{|c|c|c|c|c|}
\hline \multirow[b]{2}{*}{ Farm } & \multicolumn{3}{|c|}{ Animal age } & \multirow[b]{2}{*}{ Total number of positive animals* (\%) } \\
\hline & $\begin{array}{l}5 \text { weeks } \\
\text { No. positive/No. sample (\%) }\end{array}$ & $\begin{array}{l}15 \text { weeks } \\
\text { No. positive/No. sample (\%) }\end{array}$ & $\begin{array}{l}22 \text { weeks } \\
\text { No. positive/No. sample (\%) }\end{array}$ & \\
\hline CA1 & $1 / 6(16.6 \%)$ & $2 / 6(33.3 \%)$ & $1 / 6(16.6 \%)$ & $4 / 6(66.6 \%)$ \\
\hline CA2 & $3 / 10(30 \%)$ & $4 / 10(40 \%)$ & $3 / 10(30 \%)$ & $8 / 10(80 \%)$ \\
\hline CA3 & $4 / 10(40 \%)$ & $6 / 10(60 \%)$ & 0/10 (0\%) & $6 / 10(60 \%)$ \\
\hline MO1 & 0/10 (0\%) & 0/10 (0\%) & $1 / 10(10 \%)$ & $1 / 10(10 \%)$ \\
\hline IV1 & $6 / 10(60 \%)$ & $7 / 10(70 \%)$ & $1 / 10(10 \%)$ & $10 / 10(100 \%)$ \\
\hline IV2 & $4 / 10(40 \%)$ & $4 / 10(40 \%)$ & $3 / 10(30 \%)$ & $6 / 10(60 \%)$ \\
\hline IV3 & $2 / 8(25 \%)$ & $7 / 8(87.5 \%)$ & $3 / 8(37.5 \%)$ & $8 / 8(100 \%)$ \\
\hline IV4 & $3 / 10(30 \%)$ & $4 / 10(40 \%)$ & $0 / 10(0 \%)$ & $6 / 10(60 \%)$ \\
\hline IV5 & $4 / 10(40 \%)$ & $2 / 10(20 \%)$ & $3 / 10(30 \%)$ & $5 / 10(50 \%)$ \\
\hline MA1 & $8 / 10(80 \%)$ & $3 / 10(30 \%)$ & $1 / 10(10 \%)$ & $9 / 10(90 \%)$ \\
\hline MA2 & 7/10 (70\%) & 3/10 (30\%) & 1/10 (10\%) & $7 / 10(70 \%)$ \\
\hline MA3 & $6 / 10(60 \%)$ & $6 / 9^{* *}(66.6 \%)$ & $0 / 9^{* *}(0 \%)$ & $8 / 10(80 \%)$ \\
\hline MA4 & $6 / 10(60 \%)$ & $4 / 9^{* *}(44.4 \%)$ & $1 / 9^{* *}(11.1 \%)$ & $6 / 10(60 \%)$ \\
\hline MA5 & 7/8 (87.5\%) & 6/8 (75\%) & 0/8 (0\%) & $8 / 8(100 \%)$ \\
\hline MA6 & 7/10 (70\%) & $3 / 10(30 \%)$ & $2 / 10(20 \%)$ & 8/10 (80\%) \\
\hline Total & $\begin{array}{l}68 / 142 \\
(47.9 \%)\end{array}$ & $\begin{array}{l}59 / 140 \\
(42.1 \%)\end{array}$ & $\begin{array}{l}20 / 140 \\
(14.3 \%)\end{array}$ & $\begin{array}{c}100 / 142 \\
(70.4 \%)\end{array}$ \\
\hline
\end{tabular}

* A calf is considered to be positive if at least one out of the three samples is positive.

**The number of animals is 9 because one calf died between the age of 5 and 15 weeks.

animal's ear tag number, and accompanied by a form recording the date of sampling, the animal's sex, breed, identification number, and the mean age of the herd.

\section{Cryptosporidium detection}

After washing steps in water to eliminate potassium dichromate from the samples, DNA was extracted according to the method previously described [25] without the Cetyl TrimethylAmmonium Bromide (CTAB) and PolyVinylPyrrolidone (PVP) treatment steps. An 18S RNA gene fragment was amplified by nested PCR according to Xiao et al. [26]. The partial gp60 gene was amplified according to Gatei et al., [27]. PCR products were analyzed on $2 \%$ agarose gel and visualized by ethidium bromide staining. To ensure purity and limit the presence of PCR inhibitors, all PCR-negative samples were reprocessed. Samples were treated for oocyst purification by immunomagnetic separation (Dynabeads ${ }^{\circledR}$ anti-Cryptosporidium, Invitrogen TM, Norway) according to the manufacturer's instructions. These samples were finally processed as previously for DNA extraction and PCR amplification.

\section{Cryptosporidium species identification}

PCR products were purified on an ultracel YM50 membrane (Microcon, Millipore, Bedford, MA, USA) according to the manufacturer's instructions. DNA sequencing reactions were performed using internal primers of the nested PCR with the ABI Prism Big Dye Terminator cycle sequencing kit (Applied Biosystem, Foster City, CA, USA). Capillary electrophoresis was performed by
Genoscreen (Lille, France). Sequences were analyzed using BLAST at NCBI [28].

\section{Results}

\section{Cryptosporidium prevalence}

The prevalence of Cryptosporidium infection on 15 farms from four administrative regions in Brittany (France) was studied (Figure 1). All Cryptosporidium-positive specimens generated the expected SSU-RNA products in nested PCR and revealed that no farm was free of Cryptosporidium. The molecular analysis of 422 fecal samples revealed that 147 (34.8\%) were positive for Cryptosporidium. As shown in Table 1 , the overall prevalence of infected animals was $70.4 \%(100 / 142)$ and ranged from $10 \%$ on a farm in Morbihan (MO1) to $100 \%$ on farms in Ile-et-Vilaine (IV1, IV3) and in Mayenne (MA5). Amongst the specimens sampled from 5-week-old and 15-week-old animals, Cryptosporidium prevalence was $47.9 \%$ and $42.1 \%$, respectively (range, 0\%-87.5\%). In 22-week-old calves, the prevalence decreased to $14.3 \%$ (range, $0 \%-37.5 \%$ ). The prevalence of infection decreased as the age of the calves increased.

\section{Cryptosporidium species identification by $18 \mathrm{~S}$ rDNA sequencing}

For species identification, the 147 positive nested PCR products were sequenced. Sequence analysis from 137 readable electrophoregrams revealed the presence of C. parvum, C. bovis, and C. ryanae. One additional Cryptosporidium genotype showing 99\% identity with Cryptosporidium ubiquitum (EU827413) (previously identified as 


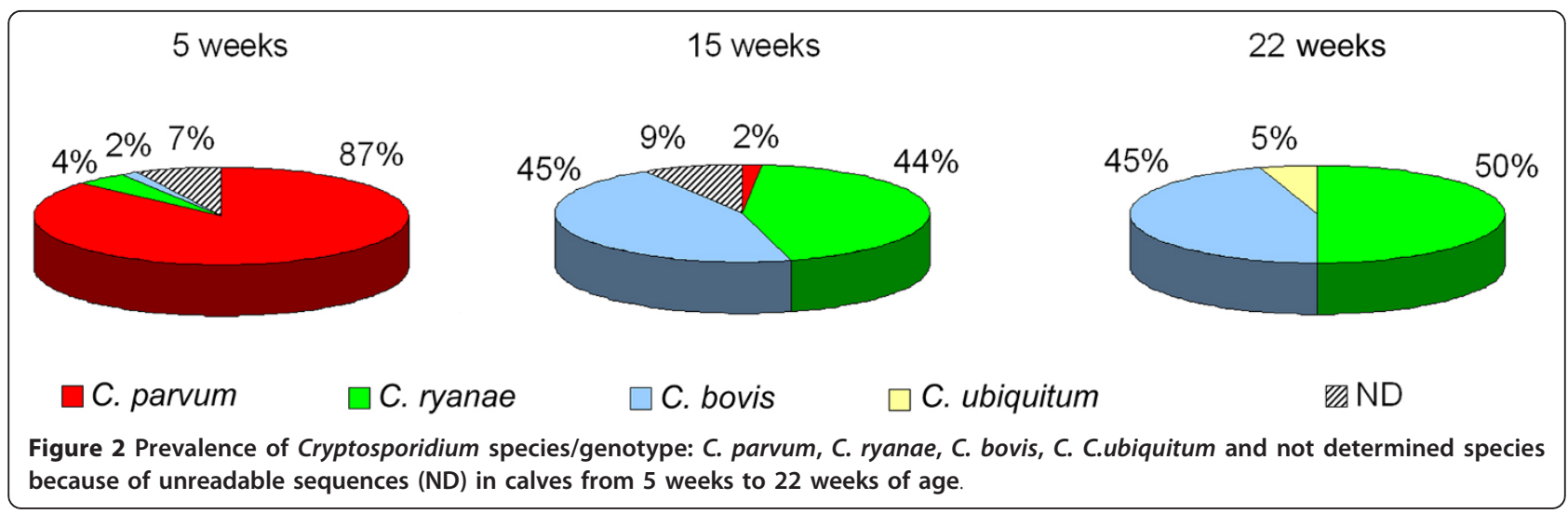

Cryptosporidium cervine genotype [13]) was detected in one calf. This sequence was deposited in GenBank under the accession number GU124629. Sixty (43.8\%) samples were identified as C. parvum as follows: forty-six sequences had 100\% identity with the GenBank AF093490 nucleotide sequence, 11 had $100 \%$ identity with the AF308600 nucleotide sequence and three had 99\% identity compared to both references. These sequences were deposited in GenBank under the accession numbers GU124615 to GU124617. For the other positive specimens, 39 (28.5\%) were identified as C. ryanae (previously described as Cryptosporidium deer-like genotype). Thirtyone of these had 100\% identity with the AY587166 sequence [17] and eight were $99 \%$ identical to this reference. These nucleotide sequences were deposited in GenBank under the accession numbers GU124621 to GU124628. For the last positive samples, 37 (27\%) had an identical nucleotide sequence with C. bovis (GenBank accession number, AY120911) formerly known as the Cryptosporidium Bovine B genotype. Within these sequences, 34 had $100 \%$ identity to the reference deposited in GenBank, three sequences had 99\% identity. These last sequences were deposited in Genbank under the accession numbers GU124618 to GU124620.

\section{Prevalence of C. parvum, C. ryanae, and C. bovis in relation to calf age}

The distribution of Cryptosporidium species identified in animals at the age of 5, 15, and 22 weeks is shown in Figure 2 . The prevalence of each species changed with the age of the calves. C. parvum prevalence was $86.7 \%$ in the 5 -week-old calves and decreased to $1.7 \%$ in 15 -week-old animals. This species was not identified in 22-week-old calves. C. ryanae and C. bovis were identified in 5-weekold calves in $4.4 \%$ and $1.5 \%$ of the specimens, respectively. The prevalence of these species in 15 -week-old animals increased to $44.1 \%$ and $45.7 \%$, respectively. This prevalence evolved to $50 \%$ and $45 \%$ in 22 -week-old animals.

\section{Sequential infection profile}

The presence of one, two, or three species of Cryptosporidium was determined in each animal $(n=91)$ for which the sequences were readable in all positive samples. Three calves positive for C. parvum at the age of 5 weeks were excluded because Cryptosporidium species could not be identified in all of the following samples collected in these animals. As shown in Table 2, Cryptosporidium species determination over time showed that only one species was identified in $63.7 \%(58 / 91)$ of the animals analyzed. Thus, $35.1 \%$ (32/91) had excreted only C. parvum, 15.4\% (14/91) shed only C. ryanae, and $12.1 \%$ (11/91) only C. bovis. The C. ubiquitum identified in one sample accounted for $1.1 \%$. In the time lapse of this study, $34 \%$ of the animals (31/91) were found to excrete two different species of Cryptosporidium successively. Indeed, 13.2\% (12/91) produced C. parvum and C. ryanae, $12.1 \%$ (11/91) excreted C. parvum and C. bovis, and $8.8 \%(8 / 91)$ excreted C. ryanae and C. bovis. Finally, 2.2\% (2/91) of the animals studied were detected to produce C. parvum, C. ryanae, and C. bovis.

\section{Cryptosporidium parvum subtyping by gp60 sequence analysis}

The subtyping analysis was performed on C. parvum positive specimens. From 60 targeted samples, 51 could be used for sequence analysis. As shown in Table 3, all alleles identified belong to the IIa family. The most common subtype IIaA15G2R1 (100\% identity with reference strain AB $514090)$ was found in 38 out of 51 samples (74.51\%). Six samples $(11.76 \%)$ were typed as subtype IIaA17G1R1 (100\% identity with reference strain GQ983359), three samples (5.89\%) as subtype IIaA16G3R1 (100\% identity with reference strain DQ192506) and two samples (3.92\%) as subtype IIaA16G2R1 (100\% identity with reference strain DQ192505). Finally one sample (1.96\%) was subtyped as IIaA16G1R1 (100\% identity with reference strain DQ192504) and another one (1.96\%) as subtype IIaA13G1R1 (100\% identity with reference strain DQ192502). 
Table 2 Number of Cryptosporidium species identified in animals and sequential infection

\begin{tabular}{|c|c|c|c|c|}
\hline $\begin{array}{c}\text { No. } \\
\text { Cryptosporidium } \\
\text { species/genotype per animal }\end{array}$ & 5 weeks & 15 weeks & 22 weeks & $n$ \\
\hline & C. parvum & & & 31 \\
\hline & C. ryanae & & & 2 \\
\hline & & C. ryanae & & 10 \\
\hline & & C. bovis & & 7 \\
\hline & & C. parvum & & 1 \\
\hline & & & C. bovis & 2 \\
\hline \multirow[t]{8}{*}{1} & & & C. ryanae & 1 \\
\hline & & & C. ubiquitum & 1 \\
\hline & & C. bovis & C. bovis & 2 \\
\hline & & C. ryanae & C. ryanae & 1 \\
\hline & C. parvum & C. ryanae & & 10 \\
\hline & C. parvum & C. bovis & & 10 \\
\hline & C. ryanae & C. bovis & & 1 \\
\hline & & C. bovis & C. ryanae & 4 \\
\hline \multirow[t]{5}{*}{2} & & C. ryanae & C. bovis & 2 \\
\hline & C. parvum & & C. ryanae & 1 \\
\hline & C. parvum & C. ryanae & C. ryanae & 1 \\
\hline & C. parvum & C. bovis & C. bovis & 1 \\
\hline & C. bovis & C. ryanae & C. ryanae & 1 \\
\hline \multirow[t]{2}{*}{3} & C. parvum & C. ryanae & C. bovis & 1 \\
\hline & C. parvum & C. bovis & C. ryanae & 1 \\
\hline$N D^{*}$ & C. parvum & ND & ND & 3 \\
\hline
\end{tabular}

ND: not determined due to unreadable sequence.

\section{Discussion}

Calves under 1 month of age are frequently infected with Cryptosporidium $s p$ [29] which results in economic loss [10]. In France, up to date, the prevalence of Cryptosporidium in diarrheic calves has been studied only by Elisa and microscopic strategies [22,23,30]. No data are available on a molecular basis to study Cryptosporidium species in calf herds in that country. The present study based on 18S rDNA and gp60 gene analysis is the first in France to include molecular characterization to describe the prevalence and the host age related susceptibility to different Cryptosporidium species after a follow up of the same animal.
Our results showed that all fifteen farms were contaminated with Cryptosporidium. The parasite prevalence on farms ranged from $10 \%$ to $100 \%$ of the sampled animals. This observation was in accordance with results in Michigan (USA) where this parameter ranged from $0 \%$ to $100 \%$ [31]. The prevalence of $70.4 \%$ obtained in this work tended toward the upper end of the scale compared to other investigations done in France which ranged from $15.6 \%$ in beef herds [30] to $95 \%$ in suckling calves [23] and in other European countries where prevalence ranged from $3.4 \%$ to $96 \%[32,33]$. However, the sampling program did not allow the study of animals under 5 weeks of age. Indeed, the animals arrived in these

Table 3 gp60 gene subtypes of $C$. parvum positive samples

\begin{tabular}{cccc}
\hline Sub-genotype & $\begin{array}{c}\text { No/No tot samples } \\
\text { (\%) }\end{array}$ & $\begin{array}{c}\text { \% identity } \\
\text { with reference }\end{array}$ & Reference sequence in GenBank \\
\hline IlaA15G2R1 & $38 / 51(74.51 \%)$ & 100 & AB514090 \\
\hline IlaA17G1R1 & $6 / 51(11.76 \%)$ & 100 & $\mathrm{GQ983359}$ \\
\hline IlaA16G3R1 & $3 / 51(5.89 \%)$ & 100 & $\mathrm{DQ} 192506$ \\
\hline IlaA16G2R1 & $2 / 51(3.92 \%)$ & 100 & $\mathrm{DQ} 192505$ \\
\hline IlaA16G1R1 & $1 / 51(1.96 \%)$ & 100 & $\mathrm{DQ192504}$ \\
\hline IlaA13G1R1 & $1 / 51(1.96 \%)$ & 100 & $\mathrm{DQ192502}$ \\
\hline
\end{tabular}

*Total number of samples (No tot samples) $=51$ because 9 C. parvum positive samples gave no readable sequence for the gp60 gene marker. 
structures at the age of 2 to 3 weeks and farmers did not allow sampling before two complete resting weeks for each animal. Therefore, our results could underestimate the real prevalence as Huetink et al. showed that the percentage of parasite excreting animal declines after the third week of age [34] and that the first peak of prevalence is at the age of 15 days [17].

In our study, the higher prevalence of cryptosporidiosis was observed in calves 5 weeks old (47.9\%) and the lowest (14.3\%) in the 22-week-old animals. This observation shows that prevalence of Cryptosporidium infection decreases with increasing age of the cattle in France as in many other countries [17,19,33-38].

Additionally, our data confirmed the presence in France of a host age-related susceptibility to the infection with different Cryptosporidium species. C. parvum was predominantly detected in 5-week-old calves (86.7\%) compared to C. ryanae or C. bovis detected in $4.4 \%$ and $1.5 \%$ of the positive samples respectively. It is noteworthy that these results are very similar to data obtained in Ireland on calves under 30 days of age with $95 \%, 3.6 \%$, and $1.3 \%$ of prevalence of the same species, respectively [39] and in the UK on animals over 3 weeks old with $93 \%$ C. parvum, $6 \%$ C. bovis, and $2 \%$ C. ryanae [40]. In contrast to previous studies $[17,41]$, C. ryanae and C. bovis were found with similar prevalence predominantly in 15 week and 22 week old calves. This association between the age of the cattle and the Cryptosporidium species identification has been supported by several studies $[17,19,21,38,40]$ but different reports suggest that Cryptosporidium species repartition regarding the age of the host could be due to a technical artifact. Despite the fact that the methodological strategy based on PCR using genus specific primers and partial direct sequencing of the $18 \mathrm{~S}$ rDNA is commonly used to identify Cryptosporidium species [42], this molecular tool is limited in the case of mixed infections. Feng et al., [19] suggested that the important shedding of C. parvum in preweaned calves had probably masked the concurrent infection of these animals by C. bovis or C. ryanae. Furthermore, previous reports suggested that a dominant Cryptosporidium species in a sample can be preferentially amplified by PCR $[43,44]$. It is noteworthy that this situation of mixed Cryptosporidium species infection in farm animals would be more prevalent than originally believed [45-47]. Mixed Cryptosporidium species could also explain sequencing difficulties encountered in this work. The simultaneous presence of several species in the same sample could lead to amplification and sequencing of different genetic fragments leading to unreadable superimposition of electrophoregrams.

Consequently, in our work based on the utilization of Cryptosporidium generic primers, the amplification of a single fragment with a single sequence is not conclusive evidence that the sample contains only a single species.
However, based on our results, it is possible to confirm the predominance of different species of Cryptosporidium by group of age among the calves.

Particularly, our data showed that animals can be sequentially infected with C. parvum, C. ryanae and C. bovis as well as C. parvum, C. bovis and C. ryanae. This observation provides evidence that a previous infection with C. parvum did not protect calves against an infection with other Cryptosporidium species. Fayer et al. suggested that the peak of cryptosporidiosis prevalence in young calves could reflect the immaturity of the immune status [48]. It was also suggested that the low excretion of C. parvum oocysts in older calves might be related to the development of immunity that also protected the animal against a secondary challenge [49]. It has been reported that immunity arises in the first two weeks after infection [50]. Interestingly, Fayer et al. [51] described that calves previously challenged with $C$. parvum were able to excrete oocysts after a second challenge with $C$. bovis but not with $C$. parvum. The authors concluded that immunity to C. parvum was not extended to C. bovis. Consistently, in our study, the presence in the same animal during sequential sampling of C. parvum, C. bovis and C. ryanae suggests that immunity against $C$. parvum and against $C$. bovis did not extend to $C$. ryanae. Furthermore, the observation that one animal excreted sequentially C. parvum, C. ryanae and $C$. bovis suggests that immunity against $C$. ryanae did not extend to C. bovis as well.

Finally, the risk to human health posed by Cryptosporidium infected cattle in France was assessed. The detection of C. ubiquitum (a rare infectious agent detected in humans [52]), C. ryanae and C. bovis (which are mainly specific for cattle) led to consider that the 22-week-old calves are not likely a public health concern. However, the major detection of C. parvum, a prevalent zoonotic species, in 5-week-old calves was in agreement with the report of Atwill et al., who considered that the contribution of cattle to human cryptosporidiosis is limited to calves under 2 months of age [53].

To determine C. parvum subtypes, the sequence analysis of a fragment of the gp60 gene was done. Our results show that in the region of Brittany, all identified C. parvum gp60 subtypes belonged to the IIa family which was previously found in both animals and humans [42]. Particularly, human infections with the IIa subtype are commonly seen in areas with intensive animal production [54]. Among the 48 gp60 subtypes formerly described in cattle [55], only six were identified in this work, being IIaA15G2R1 the most commonly found. This subtype has been widely reported in calves and humans in different countries such as in Portugal [54], Slovenia [56] and The Netherlands [57]. 
This observation confirms previous works and suggests a zoonotic transmission of the parasite also in this region.

It is noteworthy that the three predominant subtypes (IIaA15G2R1, IIaA17G1R1, and IIaA16G3R1) found in this work were also described in cattle with an equivalent distribution in The Netherlands [57] and England [40]. Thus, the subtype IIaA15G2R1 was found in 74.5\% of the samples in this work, $68.9 \%$ in The Netherlands and $68.6 \%$ in England. The IIaA17G1R1 was identified in $11.7 \%$ of the samples in this report, $10.8 \%$ in The Netherlands and 13.8\% in England. The IIaA16G3R1 determined in $5.9 \%$ of our samples, was characterized in $4.65 \%$ in The Netherlands and 5.8\% in England. It is remarkable that subtypes, IIaA16G2R1, IIaA16G1R1 and IIaA13G2R1 were equivalently underrepresented in these three countries. This observation could suggest that the proportion of a gp60 subtype would not be randomly represented in a population.

Finally, the zoonotic transmission assessment of C. parvum in France would require a comparative investigation of variable genetic loci both in human and animal samples.

This is the first report on the molecular identification of Cryptosporidium species or genotypes in veal calves in France. According to data reported previously in many countries, a sequential distribution of species is observed in cattle according to age. C. parvum was mainly observed in the youngest calves, while C. ryanae and C. bovis became predominant in stool specimens collected in older animals. In some cases, several Cryptosporidium species were successively detected in the same calf, suggesting that the immune defense against $C$. parvum is not efficient against $C$. ryanae or $C$. bovis. Finally, the major identification of the IIaA15G2R1 subtype in France suggests that 5 -week old calves could be a reservoir for zoonotic parasites transmissible to humans.

\section{Acknowledgements}

This study was supported by the Catholic University of Lille through the "Projet Grande Campagne Ensemble Innovons" genotyping program. We would like to thank the veal unit managers who participated in this study.

\section{Author details}

'Laboratoire Biotechnologies et Gestion des Agents Pathogènes, Institut Supérieur d'Agriculture, 59048 Lille, France. 'Laboratoire Biologie et Diversité des Pathogènes Eucaryotes Emergents, Institut Pasteur de Lille, 59019 Lille, France. ${ }^{3}$ INSERM U1019, Institut Pasteur de Lille, 59019 Lille, France. ${ }^{4}$ CNRS UMR8204, Institut Pasteur de Lille, 59019 Lille, France. ${ }^{5}$ Laboratoire Environnement et Santé, Faculté Libre des Sciences et Technologies, 59048 Lille, France.

\section{Authors' contributions}

JF and KG participated in the conception and design of the study, carried out the experiments and drafted the manuscript. HL designed the sampling strategy and collected samples on farms. JF, KG and AFD designed the protocol for molecular assay and participated in the analysis result. OHG carried out molecular assays. EDC, GC and PH participated in the coordination of the study and helped draft the manuscript. All authors read and approved the final manuscript.

\section{Competing interests}

The authors declare that they have no competing interests.

Received: 7 July 2011 Accepted: 2 December 2011

Published: 2 December 2011

\section{References}

1. Fayer R: Taxonomy and species delimitation in Cryptosporidium. Exp Parasitol 2009, 124:90-97.

2. Mac Kenzie WR, Hoxie NJ, Proctor ME, Gradus MS, Blair KA, Peterson DE, Kazmierczak JJ, Addiss DG, Fox KR, Rose JB, Davis JP: A massive outbreak in Milwaukee of cryptosporidium infection transmitted through the public water supply. N Engl J Med 1994, 331:161-167.

3. O'Hara SP, Chen XM: The cell biology of cryptosporidium infection. Microbes Infect 2011, 13:721-730.

4. Caccio SM, Pozio E: Advances in the epidemiology, diagnosis and treatment of cryptosporidiosis. Expert Rev Anti Infect Ther 2006, 4:429-443.

5. Chalmers RM, Giles M: Zoonotic cryptosporidiosis in the UK - challenges for control. J Appl Microbiol 2010, 109:1487-1497.

6. Monis PT, Thompson RC: Cryptosporidium and Giardia-zoonoses: fact or fiction? Infect Genet Evol 2003, 3:233-244.

7. Follet-Dumoulin A, Guyot K, Duchatelle S, Bourel B, Guilbert F, Dei-Cas E, Gosset D, Cailliez JC: Involvement of insects in the dissemination of Cryptosporidium in the environment. J Eukaryot Microbiol 2001, Suppl:36S.

8. Panciera RJ, Thomassen RW, Garner FM: Cryptosporidial infection in a calf. Vet Pathol 1971, 8:479-484.

9. Moore DA, Zeman DH: Cryptosporidiosis in neonatal calves: 277 cases (1986-1987). J Am Vet Med Assoc 1991, 198:1969-1971.

10. de Graaf DC, Vanopdenbosch E, Ortega-Mora LM, Abbassi H, Peeters JE: A review of the importance of cryptosporidiosis in farm animals. Int $J$ Parasitol 1999, 29:1269-1287.

11. Fayer R, Santin M: Cryptosporidium xiaoi n. sp. (Apicomplexa: Cryptosporidiidae) in sheep (Ovis aries). Vet Parasitol 2009, 164:192-200.

12. Robinson G, Wright S, Elwin K, Hadfield SJ, Katzer F, Bartley PM, Hunter PR, Nath M, Innes EA, Chalmers RM: Re-description of Cryptosporidium cuniculus Inman and Takeuchi, 1979 (Apicomplexa: Cryptosporidiidae): morphology, biology and phylogeny. Int J Parasitol 2010, 40:1539-1548.

13. Fayer $R$, Santin M, Macarisin D: Cryptosporidium ubiquitum n. sp. in animals and humans. Vet Parasitol 2010, 172:23-32.

14. Chalmers RM, Smith R, Elwin K, Clifton-Hadley FA, Giles M: Epidemiology of anthroponotic and zoonotic human cryptosporidiosis in England and Wales, 2004-2006. Epidemiol Infect 2011, 139:700-712.

15. Leoni F, Amar C, Nichols G, Pedraza-Diaz S, McLauchlin J: Genetic analysis of Cryptosporidium from 2414 humans with diarrhoea in England between 1985 and 2000. J Med Microbiol 2006, 55:703-707.

16. Fayer R, Santin M, Trout JM, Greiner E: Prevalence of species and genotypes of Cryptosporidium found in 1-2-year-old dairy cattle in the eastern United States. Vet Parasitol 2006, 135:105-112.

17. Santin M, Trout JM, Xiao L, Zhou L, Greiner E, Fayer R: Prevalence and agerelated variation of Cryptosporidium species and genotypes in dairy calves. Vet Parasitol 2004, 122:103-117.

18. Santin M, Trout JM, Fayer R: A longitudinal study of cryptosporidiosis in dairy cattle from birth to 2 years of age. Vet Parasitol 2008, 155:15-23.

19. Feng $Y$, Ortega $Y$, He G, Das $P, X u$ M, Zhang X, Fayer R, Gatei W, Cama V, Xiao L: Wide geographic distribution of Cryptosporidium bovis and the deer-like genotype in bovines. Vet Parasitol 2007, 144:1-9.

20. Muhid A, Robertson I, Ng J, Ryan U: Prevalence of and management factors contributing to Cryptosporidium sp. infection in pre-weaned and post-weaned calves in Johor, Malaysia. Exp Parasitol 2011, 127:534-538

21. Langkjaer RB, Vigre $H$, Enemark HL, Maddox-Hyttel C: Molecular and phylogenetic characterization of Cryptosporidium and Giardia from pigs and cattle in Denmark. Parasitology 2007, 134:339-350.

22. Lefay $D$, Naciri $M$, Poirier $P$, Chermette R: Prevalence of Cryptosporidium infection in calves in France. Vet Parasitol 2000, 89:1-9.

23. Naciri M, Lefay MP, Mancassola R, Poirier P, Chermette R: Role of Cryptosporidium parvum as a pathogen in neonatal diarrhoea complex in suckling and dairy calves in France. Vet Parasitol 1999, 85:245-257. 
24. Brscic M, Heutinck LF, Wolthuis-Fillerup M, Stockhofe N, Engel B, Visser EK, Gottardo F, Bokkers EA, Lensink BJ, Cozzi G, Van Reenen CG: Prevalence of gastrointestinal disorders recorded at postmortem inspection in white veal calves and associated risk factors. J Dairy Sci 2011, 94:853-863.

25. Guyot K, Follet-Dumoulin A, Lelievre E, Sarfati C, Rabodonirina M, Nevez G, Cailliez JC, Camus D, Dei-Cas E: Molecular characterization of Cryptosporidium isolates obtained from humans in France. J Clin Microbiol 2001, 39:3472-3480.

26. Xiao L, Alderisio K, Limor J, Royer M, Lal AA: Identification of species and sources of Cryptosporidium oocysts in storm waters with a smallsubunit rRNA-based diagnostic and genotyping tool. Appl Environ Microbiol 2000, 66:5492-5498.

27. Gatei W, Hart CA, Gilman RH, Das P, Cama V, Xiao L: Development of a multilocus sequence typing tool for Cryptosporidium hominis. J Eukaryot Microbiol 2006, 53(Suppl 1):S43-S48.

28. Basic Local Alignment Search Tool. [http://www.ncbi.nlm.nih.gov/BLAST/]

29. Quilez J, Sanchez-Acedo C, del Cacho E, Clavel A, Causape AC: Prevalence of Cryptosporidium and Giardia infections in cattle in Aragon (northeastern Spain). Vet Parasitol 1996, 66:139-146.

30. Bendali F, Bichet H, Schelcher F, Sanaa M: Pattern of diarrhoea in newborn beef calves in south-west France. Vet Res 1999, 30:61-74.

31. Peng MM, Wilson ML, Holland RE, Meshnick SR, Lal AA, Xiao L: Genetic diversity of Cryptosporidium spp. in cattle in Michigan: implications for understanding the transmission dynamics. Parasitol Res 2003, 90:175-180.

32. Duranti A, Caccio SM, Pozio E, Di Egidio A, De Curtis M, Battisti A, Scaramozzino P: Risk factors associated with Cryptosporidium parvum infection in cattle. Zoonoses Public Health 2009, 56:176-182.

33. Maddox-Hyttel C, Langkjaer RB, Enemark HL, Vigre H: Cryptosporidium and Giardia in different age groups of Danish cattle and pigs-occurrence and management associated risk factors. Vet Parasitol 2006, 141:48-59.

34. Huetink RE, van der Giessen JW, Noordhuizen JP, Ploeger HW: Epidemiology of Cryptosporidium spp. and Giardia duodenalis on a dairy farm. Vet Parasitol 2001, 102:53-67.

35. Khan SM, Debnath C, Pramanik AK, Xiao L, Nozaki T, Ganguly S: Molecular characterization and assessment of zoonotic transmission of Cryptosporidium from dairy cattle in West Bengal, India. Vet Parasitol 2001, 171:41-47.

36. Singh BB, Sharma R, Kumar H, Banga HS, Aulakh RS, Gill JP, Sharma JK: Prevalence of Cryptosporidium parvum infection in Punjab (India) and its association with diarrhea in neonatal dairy calves. Vet Parasitol 2006, 140:162-165.

37. Feltus DC, Giddings CW, Khaitsa ML, McEvoy JM: High prevalence of Cryptosporidium bovis and the deer-like genotype in calves compared to mature cows in beef cow-calf operations. Vet Parasitol 2008, 151:191-195.

38. Maikai BV, Umoh JU, Kwaga JK, Lawal IA, Maikai VA, Cama V, Xiao L: Molecular characterization of Cryptosporidium spp. in native breeds of cattle in Kaduna State, Nigeria. Vet Parasitol 2011, 178:241-245.

39. Thompson HP, Dooley JS, Kenny J, McCoy M, Lowery CJ, Moore JE, Xiao L: Genotypes and subtypes of Cryptosporidium spp. in neonatal calves in Northern Ireland. Parasitol Res 2007, 100:619-624.

40. Brook EJ, Anthony Hart C, French NP, Christley RM: Molecular epidemiology of Cryptosporidium subtypes in cattle in England. Vet $J$ 2009, 179:378-382.

41. Feng Y, Li N, Duan L, Xiao L: Cryptosporidium genotype and subtype distribution in raw wastewater in Shanghai, China: evidence for possible unique Cryptosporidium hominis transmission. J Clin Microbiol 2009, 47:153-157.

42. Xiao L: Molecular epidemiology of cryptosporidiosis: an update. Exp Parasitol 2010, 124:80-89.

43. Reed C, Sturbaum GD, Hoover PJ, Sterling CR: Cryptosporidium parvum mixed genotypes detected by PCR-restriction fragment length polymorphism analysis. Appl Environ Microbiol 2002, 68:427-429.

44. Tanriverdi S, Arslan MO, Akiyoshi DE, Tzipori S, Widmer G: Identification of genotypically mixed Cryptosporidium parvum populations in humans and calves. Mol Biochem Parasitol 2003, 130:13-22.

45. Jenikova M, Nemejc K, Sak B, Kvetonova D, Kvac M: New view on the agespecificity of pig Cryptosporidium by species-specific primers for distinguishing Cryptosporidium suis and Cryptosporidium pig genotype II. Vet Parasitol 2011, 176:120-125.
46. Santin M, Zarlenga DS: A multiplex polymerase chain reaction assay to simultaneously distinguish Cryptosporidium species of veterinary and public health concern in cattle. Vet Parasitol 2009, 166:32-37.

47. Wang $R$, Wang $H$, Sun $Y$, Zhang L, Jian F, Qi M, Ning C, Xiao L: Characteristics of Cryptosporidium transmission in preweaned dairy cattle in Henan, China. J Clin Microbiol 2011, 49:1077-1082.

48. Fayer R, Gasbarre L, Pasquali P, Canals A, Almeria S, Zarlenga D: Cryptosporidium parvum infection in bovine neonates: dynamic clinical, parasitic and immunologic patterns. Int J Parasitol 1998, 28:49-56.

49. Harp JA, Woodmansee DB, Moon HW: Resistance of calves to Cryptosporidium parvum: effects of age and previous exposure. Infect Immun 1990, 58:2237-2240.

50. Peeters JE, Villacorta I, Vanopdenbosch E, Vandergheynst D, Naciri M, AresMazas E, Yvore P: Cryptosporidium parvum in calves: kinetics and immunoblot analysis of specific serum and local antibody responses (immunoglobulin $\mathrm{A}[\mathrm{lg} \mathrm{A}], \mathrm{lg} \mathrm{G}$, and $\operatorname{lgM}$ ) after natural and experimental infections. Infect Immun 1992, 60:2309-2316.

51. Fayer R, Santin M, Xiao L: Cryptosporidium bovis n. sp. (Apicomplexa: Cryptosporidiidae) in cattle (Bos taurus). J Parasitol 2005, 91:624-629.

52. Trotz-Williams LA, Martin DS, Gatei W, Cama V, Peregrine AS, Martin SW, Nydam DV, Jamieson F, Xiao L: Genotype and subtype analyses of Cryptosporidium isolates from dairy calves and humans in Ontario. Parasitol Res 2006, 99:346-352.

53. Atwill ER, Johnson E, Klingborg DJ, Veserat GM, Markegard G, Jensen WA, Pratt DW, Delmas RE, George HA, Forero LC, Philips RL, Barry SJ, McDougald NK, Gildersleeve RR, Frost WE: Age, geographic, and temporal distribution of fecal shedding of Cryptosporidium parvum oocysts in cow-calf herds. Am J Vet Res 1999, 60:420-425.

54. Alves M, Xiao L, Antunes F, Matos O: Distribution of Cryptosporidium subtypes in humans and domestic and wild ruminants in Portugal. Parasitol Res 2006, 99:287-292.

55. Jex AR, Gasser RB: Genetic richness and diversity in Cryptosporidium hominis and C. parvum reveals major knowledge gaps and a need for the application of "next generation" technologies-research review. Biotechnol Adv 2010, 28:17-26.

56. Soba B, Logar J: Genetic classification of Cryptosporidium isolates from humans and calves in Slovenia. Parasitology 2008, 135:1263-1270.

57. Wielinga PR, de Vries A, van der Goot TH, Mank T, Mars MH, Kortbeek LM, van der Giessen JW: Molecular epidemiology of Cryptosporidium in humans and cattle in The Netherlands. Int J Parasitol 2008, 38:809-817.

doi:10.1186/1297-9716-42-116

Cite this article as: Follet et al:: Cryptosporidium infection in a veal calf cohort in France: molecular characterization of species in a longitudinal study. Veterinary Research 2011 42:116.

\section{Submit your next manuscript to BioMed Central and take full advantage of:}

- Convenient online submission

- Thorough peer review

- No space constraints or color figure charges

- Immediate publication on acceptance

- Inclusion in PubMed, CAS, Scopus and Google Scholar

- Research which is freely available for redistribution

Submit your manuscript at www.biomedcentral.com/submit
C Biomed Central 